\title{
Da rotatividade migratória à baixa migração: uma análise dos padrões da mobilidade populacional no Brasil de 1995-2000
}

\author{
Everton Emanuel Campos de Lima* \\ Fernando Gomes Braga ${ }^{* *}$
}

Este trabalho propõe uma metodologia de classificação dos municípios brasileiros conforme a característica migratória, tendo como base as informações disponíveis no Censo Demográfico de 2000. Foram aplicadas análises multivariadas de redução e classificação de dados sobre um conjunto de variáveis selecionadas que descrevem a forma como os 5.507 municípios se articulam na rede migratória brasileira. Primeiramente, aplicou-se uma análise de componentes principais com a finalidade de reduzir o conjunto de variáveis originais em componentes não correlacionados entre si. Posteriormente, estes componentes foram empregados numa análise classificatória de cluster com o objetivo de estabelecer uma tipologia migratória das localidades em estudo. Os resultados mostraram que há importantes diferenciais na inserção dos municípios na rede migratória, na qual existe um grande número de lugares pouco conectados em contraste com um número pequeno de pontos que experimentam fortes conexões, e nos quais a população circula rapidamente. A classificação aponta para a existência de novas categorias de lugares, além das definições clássicas de atração e repulsão, como a rotatividade migratória.

Palavras-chave: Rotatividade migratória. Baixa migração. Mobilidade populacional

\footnotetext{
* Doutor e pós-doutor em Demografia, pesquisador do Departamento de Demografia da Universidade Federal de Minas Gerais (everton.emanuel@gmail.com).

** Doutor em Demografia na Universidade Federal de Minas Gerais, mestre em Geografia, professor do Instituto Federal de Minas Gerais, campus Ouro Preto - IFMG-OP (braga@ifmg.edu.br).
} 


\section{Introdução}

Este trabalho tem como objetivo principal apresentar uma proposta de classificação dos municípios brasileiros a partir dos padrões observáveis das migrações internas. Tal esforço metodológico justifica-se diante das reconfigurações pelas quais passa o fenômeno migratório, que acompanha a reestruturação territorial do país. Eventos como a desconcentração produtiva, a diversificação de mercados, a urbanização de áreas rurais, a metropolização e a expansão da fronteira agrícola conformam um rol de novas e velhas potencialidades para a realocação da mão de obra pelo país. Esse conjunto de fatores associados sugere a formatação de novos padrões para a mobilidade populacional no Brasil, constituídos pela sobreposição de condições presentes e passadas, que imprimem um novo ritmo aos movimentos populacionais e inserem novos significados para a integração territorial.

O Censo Demográfico de 2000 constitui uma rica fonte de dados sobre as migrações internas intermunicipais, permitindo o cruzamento das informações individuais dos migrantes com as características econômicas e sociais dos municípios de origem e destino. Desta forma, procurou-se identificar um conjunto de indicadores, estimados a partir das informações censitárias, que permitissem visualizar os padrões de inserção dos municípios no conjunto das trocas migratórias internas do país. Após a realização de uma análise de classificação com esses indicadores, foi possível discutir a formação de categorias de municípios, que se diferenciam, sobretudo, em função de dois fatores: a tendência predominante de atrair ou expulsar determinados grupos populacionais; e o grau de articulação destes municípios com a rede migratória nacional, dado tanto pela extensão das conexões como pelo volume dos fluxos envolvidos.

Na discussão sobre os novos padrões migratórios, podem ser diferenciadas duas categorias de análise: as pessoas e os lugares. Pensar em novos padrões migratórios sob a perspectiva das pessoas permite focalizar os estudos nas transformações experimentadas pelos grupos sociais, ao longo do tempo, no que se refere a escolarização, renda, qualificação e inserção profissional e motivos da migração. Estudar as pessoas também possibilita avaliar as conexões entre elas, quais sejam, as redes sociais que dão suporte aos movimentos e que podem ter alterado seu conteúdo em meio às transformações no conjunto de oportunidades abertas para a mobilidade populacional. Por outro lado, é possível investigar o surgimento dos novos padrões migratórios a partir do estudo dos lugares. Neste sentido, torna-se importante lançar luz sobre a organização do território, entendido como espaço de construção das relações de poder na sociedade. O território - mais do que simples receptáculo - constitui, ele mesmo, uma identidade, manifestada pela interação entre os fatores físicos e humanos que dão forma ao processo de desenvolvimento econômico e social. Assim, é fundamental considerar como cada "lugar" tem contribuído no conjunto das trocas populacionais, a fim de compreender as relações entre as transformações no fenômeno migratório e a reordenação territorial. Este trabalho se ocupará em investigar este último aspecto. 
Para tanto, primeiramente, é feita uma breve discussão teórica sobre os possíveis “novos padrões" da migração interna brasileira, seguida por uma exposição da metodologia de análise aqui empregada, a apresentação dos procedimentos de análise multivariada e, finalmente, a discussão dos resultados encontrados.

\section{Novos padrões e a categorização dos lugares da migração}

O padrão recente da migração interna no Brasil tem se configurado como um desafio teórico e empírico para os analistas do tema. A partir da década de 1980 percebe-se uma diminuição da intensidade dos movimentos internos associados ao êxodo rural e à ocupação da fronteira agrícola. Esse novo contexto tem conduzido os especialistas a indagarem sobre a emergência de novos padrões migratórios, com características inovadoras em termos tanto das direções como da intensidade dos fluxos (PACHECO; PATARRA, 1997). Portanto, é de fundamental importância empreender esforços para uma descrição mais acurada da mobilidade populacional no Brasil, o que pode resultar na identificação de outras categorias que atendam à recente complexidade criada pelos novos padrões.

Como características principais destes novos padrões, podem-se citar: diminuição das distâncias percorridas pelos migrantes; diversificação das rotas migratórias; esgotamento do êxodo rural; predominância dos fluxos urbano-urbano; aumento dos fluxos urbano-rurais; desconcentração demográfica; aumento da migração de retorno; crescimento das migrações de curta duração; entre outros (MATOS, 1995, 2002; BRITO, 2006). A complexidade destes novos processos tem reduzido o potencial de explicação de antigas categorias espaciais do fenômeno migratório. Polarizar os lugares apenas como de "atração" e "repulsão" populacional parece não mais corretamente descrever as dinâmicas mais complexas da mobilidade populacional.

Uma das primeiras contribuições para a identificação de categorias migratórias é o texto de Lee (1980), que sintetiza o processo como um evento social desencadeado pela existência de três grandes conjuntos de fatores. Os primeiros são aqueles que determinam a expulsão do lugar de origem, sendo o fluxo direcionado para os espaços nos quais se observassem os fatores de atração. Entre os fatores de expulsão e os de atração atuariam os mecanismos intervenientes, de natureza diversa, e com efeito diferenciado sobre a decisão individual de migrar. ${ }^{1}$ É importante destacar que tal abordagem compreende o ato migratório como um fenômeno pertencente ao campo da decisão individual, com forte influência de características e predisposições no campo psicológico. De qualquer sorte, é possível desprender desta abordagem uma feição espacial do fenômeno, que define os lugares como de atração ou repulsão, concepção recorrentemente observada nos trabalhos de inspiração neoclássica (HARRIS; TODARO, 1980; BORJAS, 1996; SJAASTAD, 1980).

\footnotetext{
${ }^{1}$ Os mecanismos intervenientes consistem nos elementos econômicos, sociais e psicológicos que aumentam o custo da mobilidade: distância, custos da viagem, rompimento dos laços afetivos na origem, insegurança sobre o sucesso no destino, entre outros (LEE, 1980).
} 
A abordagem histórico-estrutural, de inspiração marxista, se opõe às explicações centradas nos sujeitos, argumentando que é a estrutura social, organizada pelas relações de exploração entre as classes, que determinará a intensidade e a direção dos fluxos populacionais. A dimensão geográfica desta teoria é evidente, já que a migração seria um resultado da produção capitalista do espaço, que realoca a mão de obra de acordo com os mecanismos de diferenciação da mesma, necessários à manutenção da lógica de exploração. Essa relação dialética no âmbito espacial também remete à noção de duas categorias de lugares: aqueles marcados pela atração populacional, nos quais o desenvolvimento das forças produtivas gera demanda por trabalhadores; e aqueles marcados pela repulsão populacional, onde o baixo desenvolvimento das forças produtivas pressiona o mercado de trabalho, estimulando a realocação da mão de obra. Neste contexto, a decisão individual se circunscreve à possibilidade de optar por qual será o lugar, entre os centros de atração, no qual se realizará a venda da força de trabalho (SINGER, 1980; GAUDEMAR, 1977).

As abordagens neoclássica e histórico-estruturalista divergem quanto à escala do fenômeno: enquanto a primeira focaliza suas interpretações nos indivíduos ou famílias, a segunda trabalha com os determinantes da estrutura social sobre os movimentos. Não obstante, o tratamento dado aos espaços da migração nas formulações teóricas parece convergir para uma leitura dualista do papel cumprido pela rede de lugares. Enquanto uma série de localidades é capaz de atrair as pessoas em função do seu dinamismo econômico, resta a outros espaços ceder população. Classificar os lugares como "de atração" ou "de repulsão” a partir do saldo migratório é, assim, a forma mais básica de compreender os determinantes espaciais do fenômeno. Contudo, a emergência de novos padrões migratórios insere novas dificuldades aos estudos, tendo em conta que, com a diversificação recente dos tipos de movimentos, também se multiplicam as formas de participação dos lugares na rede migratória. Sem dúvida, a melhor compreensão desse fenômeno representa um dos maiores desafios recentes para o estudo das migrações internas brasileiras.

Considerando essas dificuldades no campo teórico, alguns autores já começam a se valer de conceitos que expressam melhor tanto a condição de imigrante como as características dos lugares que os recebem e enviam. A separação conceitual entre mobilidade pendular e migração, cujos limites poderiam ser facilmente demarcados em tempos de forte êxodo rural e ocupação de fronteira agrícola, agora se dilui em ocorrências diversas de intensa movimentação de curta duração, seguindo a fluidez espacial de atividades econômicas, como a construção civil, a agricultura, o surgimento de tecnopolos, entre outros (GOLGHER, 2006). Da mesma forma, torna-se insuficiente classificar os lugares apenas como de atração ou repulsão, dada a forte circularidade observada na rede migratória nacional, o que tem estimulado a menção de categorias como a "rotatividade migratória” para compreensão da dinâmica de espaços que enviam e recebem grande quantidade de migrantes simultaneamente (BAENINGER, 2008).

Assim, para compreender a migração interna brasileira, torna-se indispensável considerar que este fenômeno constitui apenas mais um dos fluxos que compõem as redes territoriais 
em mutação no território brasileiro. Desta maneira, as categorizações precisam ir além das simples divisões entre espaços de atração e repulsão, buscando captar a maior diversidade das formas de inserção das localidades nas redes migratórias. Considerando a importância destas questões, a proposta metodológica apresentada a seguir consiste em um esforço introdutório para o reconhecimento mais preciso dos lugares da migração no Brasil.

\section{Metodologia}

A proposta aqui apresentada de classificação dos municípios brasileiros quanto à tendência migratória apoia-se em dois pressupostos básicos:

- os municípios são considerados a melhor aproximação do conceito de "lugar", que é entendido aqui como o recorte espacial que delimita os espaços de vida, nos quais se desenvolvem as atividades que compõem a prática da cidadania e onde primeiro podem ser percebidos os efeitos positivos e negativos da migração. Os lugares, assim, constituem os vértices das redes de fluxos migratórios;

- os fluxos migratórios, por sua vez, sintetizam parte significativa das conexões estabelecidas entre os lugares, já que, geralmente, a decisão de para onde migrar apoia-se na preexistência de laços econômicos, culturais, afetivos, solidários, etc., entre os lugares. Neste sentido, o reconhecimento dos novos padrões migratórios sob a ótica da participação dos lugares pode revelar aspectos mais amplos do que aqueles relacionados à temática da migração interna.

Assim, os 5.507 municípios brasileiros existentes em 2000 constituíram a unidade básica de análise deste estudo. Contudo, tendo em conta que a abordagem aqui proposta trata de todo o espaço nacional, preferiu-se considerar que as Regiões Metropolitanas (RMs) representam apenas uma localidade, dado que os migrantes residentes em qualquer município das RMs provavelmente participam dos mercados de trabalho e consumo de toda a região. Assim, para efeito das análises, foram agregados os municípios de nove Regiões Metropolitanas: Belém, Fortaleza, Recife, Salvador, Belo Horizonte, Rio de Janeiro, São Paulo, Curitiba e Porto Alegre. Desta maneira, na proposta de classificação, trabalhou-se com 5.311 localidades² em todo o país.

As informações sobre fluxos migratórios entre as localidades foram coletadas a partir dos microdados da amostra do Censo Demográfico de 2000, realizado pelo Instituto Brasileiro de Geografia e Estatística (IBGE). De acordo com as definições da pesquisa (IBGE, 2002), são considerados migrantes todos os indivíduos que realizaram mudança permanente de residência entre municípios no período de 1995 a 2000. A variável que permite controlar a procedência dos migrantes no Censo de 2000 possibilita captar os migrantes de data-fixa, que reúnem os indivíduos que declararam o local de residência anterior no dia 31/07/1995.3

\footnotetext{
${ }^{2}$ Considerando-se que os espaços trabalhados são formados por municípios e agregações de municípios, ao longo do texto o termo "localidades" será usado para designar o conjunto destas unidades espaciais.

3 Tendo em conta a forma de declaração da procedência, para efeito da identificação dos migrantes de data-fixa são desconsiderados todos os migrantes que residiam no mesmo município no fim e no início do período (31/07/1995 e 01/08/2000, respectivamente), bem como as crianças com menos de cinco anos de idade.
} 
Quanto às técnicas utilizadas para criação da tipologia migratória em 2000, foram realizados dois procedimentos. No primeiro momento empregou-se uma análise fatorial por meio do método de componentes principais. Os componentes principais estimados foram, então, utilizados no segundo procedimento para uma análise de cluster, que deu origem à classificação aqui proposta. Selecionou-se um conjunto de informações que sintetizassem os aspectos mais importantes da inserção das localidades na rede migratória, quais sejam:

- saldo migratório - estimado pela diferença entre imigrantes e emigrantes em cada localidade. Este indicador permite uma fácil interpretação do padrão migratório, já que polariza os lugares entre atrativos (saldo positivo) e repulsivos (saldo negativo);

- percentual de imigrantes - calculado a partir da razão entre o total de migrantes que declararam residir na localidade na data de referência do Censo e a população total da localidade. Esse indicador mostra a força da atratividade exercida pela localidade relativamente ao tamanho demográfico da mesma;

- percentual de emigrantes - obtido a partir da razão entre o total de migrantes que declararam residir na localidade em 31/07/1995 e a população total das localidades em 2000. A interpretação deste indicador tem sentido inverso do anterior, representando a força relativa da repulsão;

- população total - total de pessoas residentes na localidade na data de referência do Censo. Essa informação é importante para a classificação, tendo em vista que a população brasileira se distribui de forma assimétrica pelo território, fato que interfere na escolha dos migrantes e, consequentemente, nas rotas dos fluxos;

- índice de eficácia migratória - resulta da razão entre o saldo migratório e o total de imigrantes e emigrantes $(I-E / I+E)$. Este indicador, assim como o saldo migratório, fornece uma noção da capacidade de absorver ou repelir população em relação ao total de pessoas cujos movimentos envolveram a localidade;

- grau de centralidade médio - essa medida apresenta a média entre dois valores: a quantidade de municípios para os quais a localidade enviou migrantes e a quantidade de municípios dos quais a localidade recebeu migrantes. Esse indicador traz informações sobre a centralidade das localidades na rede migratória, considerando que a centralidade é tão maior quanto maior for a quantidade de vínculos que a localidade estabelece.

\section{Análise multivariada}

\section{Análise de componentes principais}

O propósito da análise fatorial é descobrir um padrão resumo das relações entre um conjunto de variáveis. Em particular, procura-se descobrir se as variáveis observadas podem ser em grande parte, ou inteiramente, explicadas em termos de um número menor de variáveis ou fatores (MINGOTI, 2007). Assim, o objetivo da análise fatorial é a parcimônia, procurando definir o relacionamento entre as variáveis de modo simples e usando um número de fatores menor que a quantidade original de variáveis. Uma variante da análise fatorial, aqui utilizada, é a análise de componentes principais (ACP).

O conceito inicial de ACP é intimamente ligado à representação ou criação de medidasresumo, dado um conjunto de informações iniciais. Em termos práticos, a intenção é reduzir 
um grande número de variáveis $p$ por meio de um pequeno número de funções lineares $m$, que melhor resume o grande grupo inicial de covariáveis. Isto ocorre pela construção de combinações lineares das variáveis originais (MINGOTI, 2007). Segundo Darlington (2010), existem inúmeras soluções matemáticas para esse problema. No entanto, o estabelecimento de três condições fornece uma única solução matemática para qualquer banco de dados, quais sejam: as funções lineares derivadas não devem ser correlacionadas; os grupos de funções lineares $m$ devem incluir funções para agrupamentos menores; e os pesos quadrados que definem cada função linear devem somar em 1. Cumpridas estas três condições, os componentes principais estimados, representados em $m$ funções lineares, declinam em importância com o aumento da variância (Tabela 1).

TABELA 1

Total da variância explicada por meio dos componentes principais, estimados a partir das variáveis que descrevem características migratórias dos municípios brasileiros

1995-2000

\begin{tabular}{|c|c|c|c|c|c|c|c|}
\hline \multirow[b]{2}{*}{$\begin{array}{c}\text { Quantidade } \\
\text { de } \\
\text { componentes }\end{array}$} & \multicolumn{3}{|c|}{ Autovalores iniciais } & \multicolumn{4}{|c|}{ Soma quadrada dos componentes rotacionados } \\
\hline & Total & $\begin{array}{c}\% \text { da } \\
\text { variância }\end{array}$ & $\begin{array}{c}\% \\
\text { cumulativa }\end{array}$ & $\begin{array}{c}\text { Quantidade } \\
\text { de } \\
\text { componentes }\end{array}$ & Total & $\begin{array}{c}\% \text { da } \\
\text { variância }\end{array}$ & $\begin{array}{c}\% \\
\text { cumulativa }\end{array}$ \\
\hline 1 & 2,004 & 33,407 & 33,407 & 1 & 1,841 & 30,676 & 30,676 \\
\hline 2 & 1,829 & 30,476 & 63,883 & 2 & 1,672 & 27,874 & 58,550 \\
\hline 3 & 1,095 & 18,246 & 82,129 & 3 & 1,415 & 23,579 & 82,129 \\
\hline 4 & 805 & 13,411 & 95,540 & & & & \\
\hline 5 & 171 & 2,849 & 98,389 & & & & \\
\hline 6 & ,097 & 1,611 & 100,000 & & & & \\
\hline 7 & 2,004 & 33,407 & 33,407 & & & & \\
\hline
\end{tabular}

Fonte: IBGE. Censo Demográfico de 2000.

Para esse estudo, a importância da utilização das técnicas de análise fatorial (neste caso, componentes principais) deve-se ao fato de que muitos dos vetores de informação das análises são redundantes, característica que causaria problemas na posterior análise de cluster. Portanto, a APC permite transformar um conjunto de variáveis originais e intercorrelacionadas num novo conjunto de variáveis ortogonais não correlacionadas entre si, ou componentes principais (RODRIGUES; BRANCO, 2006). Deste modo, optou-se por reduzir o conjunto de informações das seis variáveis originais em medidas-resumo. Os resultados da análise de componentes principais são descritos por uma matriz de componentes rotacionados (Tabela 2 ).

Foi empregado o método de rotação Varimax que minimiza as variáveis em cada componente. O objetivo da rotação consiste em delinear os fatores por meio do recurso de transformação ortogonal das variáveis originais, ${ }^{4}$ de tal modo que eles correspondam

\footnotetext{
${ }^{4}$ A rotação é geralmente aplicada quando a suposição de ortogonalidade dos fatores está sendo violada, e a partição das variáveis originais em $m$ grupos não é clara ou difícil de ser justificada.
} 
a agrupamentos de variáveis inter-relacionadas, ou seja, os fatores são rodados até que correspondam a uma estrutura mais simples do construto investigado (MINGOTI, 2007). A quantidade de componentes foi definida a partir dos autovalores, segundo a regra empírica de Henry Kaiser. Ele sugere que o número de componentes, para a reconstrução das informações dos itens iniciais, deve possuir um autovalor maior que 1 (MINGOTI, 2007; DARLINGTON, 2010).

TABELA 2

Matriz de correlação dos componentes rotacionada pelo método Varimax, estimada a partir das variáveis que descrevem características migratórias dos municípios brasileiros

$1995-2000$

\begin{tabular}{|c|c|c|c|}
\hline \multirow{3}{*}{ Variáveis } & \multicolumn{3}{|c|}{ Componentes } \\
\hline & Rotativo & Atração & Repulsão \\
\hline & 1 & 2 & 3 \\
\hline População total & 0,948 & $-0,112$ & $-0,046$ \\
\hline Grau de centralidade médio & 0,923 & 0,056 & 0,03 \\
\hline Percentual de imigrantes & 0,104 & 0,935 & 0,138 \\
\hline Índice de eficácia migratória & 0,074 & 0,713 & $-0,617$ \\
\hline Saldo migratório & $-0,269$ & 0,523 & $-0,198$ \\
\hline Percentual de emigrantes & 0,009 & $-0,023$ & 0,986 \\
\hline
\end{tabular}

Fonte: IBGE. Censo Demográfico de 2000.

Nota: Método de extração: análise de componentes principais. Método de rotação: Varimax com normalização Kaiser.

De acordo com os autovalores, considerando-se os valores acima de 1 , tem-se que as seis variáveis iniciais foram reduzidas para três componentes ortogonais e independentes entre si. Os três componentes combinados explicam algo em torno de $82 \%$ da variabilidade do conjunto original. Isto quer dizer que mais de 4/5 da informação inicial pôde ser comprimida em três componentes ortogonais e independentes. Tais componentes agora não mais possuem informações relativas ou absolutas contidas nos itens iniciais. Na verdade, por meio da análise multivariada de componentes principais, as covariáveis são transformadas em componentes padronizados com valores numéricos, ou escores, que vão de - $\infty$ a $+\infty$, média centrada em zero e desvio-padrão igual a 1 (MINGOTI, 2007). O próximo passo é discernir cada um dos itens do construto investigado, de acordo com a matriz de correlações. A partir da análise das correlações entre os três componentes estimados e as variáveis originais da Tabela 2, podem-se descrever os fatores da seguinte forma:

- o primeiro componente principal é definido por localidades muito populosas $(0,948) \mathrm{com}$ alto grau de centralidade $(0,923)$, tendo o saldo migratório como uma variável de pequena importância na sua definição $(-0,269)$. Por possuir muitos vínculos com outras localidades, tanto no envio como na recepção de migrantes, definiu-se que este componente sintetiza a emergência dos novos padrões, dado que não polariza as localidades entre atração ou repulsão. Assim, tendo em conta que tais localidades realizam múltiplas conexões tanto na entrada como na saída de migrantes, optou-se por denominar este componente como rotativo; 
- o segundo componente principal possui alta associação com indicadores sintomáticos do poder atrativo: percentual de imigrantes $(0,935)$, índice de eficácia migratória $(0,713)$ e saldo migratório $(0,523)$, ambos positivamente correlacionados. Isto significa que um alto escore nesta componente principal é condizente com áreas compostas por um grande percentual de imigrantes em sua população. Portanto, considerou-se este componente indicador da dimensão migratória da atração;

- o terceiro componente principal indica uma dimensão do construto oposta ao segundo, possuindo alta correlação com elementos que descrevem áreas de repulsão: alta correlação com o percentual de emigrantes $(0,986)$ e correlações negativas com o índice de eficácia migratória $(-0,617)$ e saldo migratório $(-0,198)$. Em outras palavras, quanto maior for o valor da proporção de emigrantes na população da área considerada, maior será o valor numérico deste componente. Do mesmo modo que, quanto menor for o saldo migratório e eficácia migratória da localidade, maior será o escore deste fator.

Uma vez descrito cada componente, o próximo passo foi efetuar uma análise de cluster com base nos três componentes padronizados.

\section{Análise de cluster}

Para a análise de cluster foi aplicado um algoritmo de partição, comumente utilizado para análises classificatórias de grandes bancos de dados, denominado two-step cluster. ${ }^{5}$ Este algoritmo é uma extensão dos modelos de agrupamento baseado em distâncias usadas por Banfield e Raftery (1993), com aplicações para atributos categóricos e contínuos ao mesmo tempo.

Tal algoritmo utiliza um princípio similar ao Birch (ZHANG et al., 1996), o qual afirma que um grande banco de dados pode ser efetivamente agrupado caso este possa ser reduzido em bancos menores. Uma grande vantagem do two-step é a possibilidade automática de encontrar o valor ótimo de agrupamentos, caso este seja desconhecido. Isto se dá por meio das informações estatísticas providas pelo critério de informação bayesiano (BIC ou CIB) proposto por Fraley e Raftery (1998), como descrito na Tabela 3.

O algoritmo estima, primeiramente, o BIC para cada número de clusters dentro de um alcance específico, e usa isto como estimador inicial para definir a quantidade ótima de agrupamentos (SPSS, 2001). Numa segunda etapa ele refina o primeiro estimador encontrando a maior mudança em distâncias entre dois agrupamentos próximos (SPSS, 2001). A distância entre dois clusters é definida, então, pela redução em log-verossimilhança (estimado por meio de uma distribuição normal para dados contínuos e multinomial para dados categóricos), após combiná-los num único agrupamento. Mais adiante, o two-step assume que tanto as variáveis dentro dos clusters como cada agrupamento são independentes entre si (SPSS, 2001). Tal condição foi garantida pela análise prévia de componentes principais.

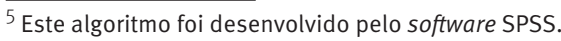


TABELA 3

Quantidade de clusters estimados pelo critério bayesiano e com base nas informações dos componentes principais que descrevem características migratórias dos municípios brasileiros

1995-2000

\begin{tabular}{ccccc}
\hline $\begin{array}{c}\text { Número de } \\
\text { clusters }\end{array}$ & $\begin{array}{c}\text { Critério bayesiano } \\
\text { de Schwarz (BIC) }\end{array}$ & $\begin{array}{c}\text { Variação em BIC } \\
(\mathbf{1})\end{array}$ & $\begin{array}{c}\text { Razão da variação } \\
\text { em BIC } \\
\text { (2) }\end{array}$ & $\begin{array}{c}\text { Razão das medidas } \\
\text { de distância } \\
\text { (3) }\end{array}$ \\
\hline 1 & 11094 & & & 2,01 \\
2 & 7761 & -3333 & 1,00 & 1,65 \\
3 & 6132 & -1629 & 0,49 & 1,17 \\
4 & 5163 & -969 & 0,29 & 2,03 \\
5 & 4343 & -820 & 0,25 & 1,20 \\
6 & 3966 & -378 & 0,11 & 1,19 \\
7 & 3659 & -307 & 0,09 & 1,29 \\
8 & 3409 & -250 & 0,07 & 1,14 \\
9 & 3228 & -181 & 0,05 & 1,34 \\
10 & 3074 & -154 & 0,05 & 1,03 \\
11 & 2972 & -102 & 0,03 & 1,03 \\
12 & 2874 & -98 & 0,03 & 1,61 \\
13 & 2780 & -94 & 0,03 & 1,00 \\
14 & 2741 & -39 & 0,01 & 1,17 \\
15 & 2702 & -39 & 0,01 & \\
\hline
\end{tabular}

Fonte: IBGE. Censo Demográfico de 2000.

(1) As variações são decorrentes do número anterior de clusters na tabela.

(2) As variações em razões são relativas às mudanças para duas soluções de agrupamento.

(3) As razões das medidas de distância são baseadas no número corrente de clusters em comparação com a quantidade de clusters anterior.

O critério de informação bayesiano é computado para cada potencial número de clusters. Os menores valores de BIC indicam uma melhor solução numérica de agrupamentos. Contudo, há casos em que o BIC se reduz ao passo que a quantidade de agrupamentos aumenta, porém, sem melhorias na solução do número de clusters (medida pelas variações em BIC) que se tornam cada vez mais complexas. Nestes casos, uma alternativa é observar as variações em BIC e nas medidas de distância. Uma boa solução apresentará uma razão razoavelmente grande de variação em BIC e uma grande razão de medidas de distância. Assim, os resultados apontam para uma melhor solução de cinco agrupamentos, com valores, respectivamente, de 0,25 e 2,03 para as razões de variação em BIC e razões de medidas de distância (SPSS, 2001).

\section{Resultados das análises}

Os resultados da análise de cluster são apresentados na Tabela 4, contendo as médias ou centroides ${ }^{6}$ dos clusters. A variação de tonalidade nas colunas indica a hierarquia de valores em cada uma, permitindo verificar as principais características de cada cluster. Os tons

\footnotetext{
${ }^{6}$ Os clusters são constituídos por uma área que agrupa n-informações, cujo centroide localiza-se topologicamente no centro desta nuvem de informações. Desta maneira, utilizam-se os conceitos de centroide e média como sinônimos.
} 
mais escuros significam valores mais altos, assim como tons claros expressam valores mais baixos. Com base nos valores dos centroides de cada agrupamento, procurou-se identificar quais padrões migratórios definem melhor os grupos de localidades.

TABELA 4

Resultado da análise de cluster, estimada a partir dos componentes principais que descrevem características migratórias dos municípios brasileiros

$1995-2000$

\begin{tabular}{cccccc}
\hline $\begin{array}{c}\text { Quantidade } \\
\text { de clusters }\end{array}$ & $\begin{array}{c}\text { Componente de } \\
\text { rotatividade }\end{array}$ & $\begin{array}{c}\text { Componente } \\
\text { de atração }\end{array}$ & $\begin{array}{c}\text { Componente } \\
\text { de repulsão }\end{array}$ & Localidades & Classificação \\
\hline 1 & 0,402 & 1,853 & $-0,211$ & 539 & Atração \\
2 & $-0,014$ & 0,123 & 1,290 & 1.252 & Repulsão \\
3 & $-0,077$ & 0,102 & $-0,798$ & 1.845 & BM-atração \\
4 & 7,829 & 1,304 & 0,049 & 27 & Rotativo \\
5 & $-0,163$ & $-0,835$ & $-0,018$ & 1.648 & BM-repulsão \\
\hline
\end{tabular}

Fonte: IBGE. Censo Demográfico de 2000.

Nota: As tonalidades de cores distinguem os valores médios de cada componente entre os clusters. Tonalidades mais escuras refletem valores médios mais altos do componente, observando nas colunas. Nas linhas, têm-se a distinção de cada cluster, dado o valor médio correspondente de cada componente.

O primeiro cluster apresenta a média mais elevada no componente de atração $(1,853)$, assim como o segundo maior valor no componente de rotatividade $(0,402)$, enquanto no componente de repulsão esse cluster tem o quarto maior valor $(-0,211)$. Desta maneira, pode-se inferir que esse conjunto de localidades agrega-se em torno do seu maior potencial atrativo, participando ativamente da rede migratória nacional no recebimento de migrantes. Em função desta característica, denominou-se esse grupo como localidades de atração. No caso do segundo agrupamento, percebe-se uma tendência oposta ao anterior. Esse é o cluster que apresenta o maior valor médio do componente de repulsão (1,290), além do terceiro maior valor nos componentes de atração e rotatividade (0,123 e -0,014, respectivamente). Assim, tem-se um grupo de localidades que também participam ativamente da rede migratória, contudo com tendência predominante a expulsar a população. Em função disto, denominou-se esse grupo de localidades de repulsão.

É interessante notar que a aplicação da metodologia resultou no reconhecimento destes dois grupos, que concentram 1.791 das 5.311 localidades (cerca de 33,72\%), nos quais o papel da migração parece ser importante para a composição demográfica dos municípios, e nos quais seria aplicável a ideia corrente de dicotomizar os lugares em atrativos e repulsivos. Contudo, há aproximadamente $66 \%$ das localidades brasileiras que não se enquadraram exatamente neste padrão e para as quais as interpretações necessitarão de maior esforço de junção entre os apontamentos teóricos e as observações empíricas.

Para proceder à interpretação dos três clusters restantes, é importante focalizar os mesmos de forma comparativa. Os clusters 3 e 5 dividem quase igualmente 3.493 localidades (65,7\% do total), enquanto o cluster 4 apresenta apenas 27 lugares. Essa subdivisão é 
curiosa e sugere que nos grupos 3 e 5 serão observados padrões já recorrentes, devido à amplitude de alcance das características observadas. Já no grupo 4 é possível que se observe algum padrão bem específico das poucas localidades que o mesmo agrega. De fato, uma leitura da distribuição dos valores centrais de cada cluster da Tabela 4 mostra que os agrupamentos 3 e 5, assim como os clusters 1 e 2, apresentam tendências opostas entre si. 0 grupo 3 tem o 4으 maior valor no componente de atração e rotatividade $(0,102$ e -0,077, respectivamente), assim como a menor média no componente da repulsão $(-0,798)$. O cluster 5 , por sua vez, registra o 3 ํ maior valor no componente de repulsão $(-0,018)$ e 0 menor valor nos componentes de atração e rotatividade $(-0,853$ e -0,163).

O fato de estes dois clusters concentrarem os menores valores médios nas distribuições indica que a migração provavelmente cumpre papel menos importante nestes lugares, se comparados aos grupos da atração e repulsão. Tendo em conta a extensão do território nacional e as transformações no conjunto de oportunidades abertas pela migração, é razoável pensar que, assim como os municípios brasileiros, em sua maioria, são pequenos e mal conectados na rede urbana nacional em função das distâncias e da carência em infraestrutura, os mesmos também se conectam de forma deficiente nas redes migratórias. Neste caso, propõe-se a identificação de uma nova categoria na descrição da articulação dos lugares na rede migratória: as localidades de baixa migração. Esse conjunto de lugares provavelmente concentra os municípios de porte pequeno nos quais a migração tem papel menor na composição demográfica. A falta de conexões provavelmente associa-se ao baixo dinamismo econômico, contudo, as análises aqui realizadas não permitem muitas conclusões neste sentido.

Como o cluster 3 apresenta maiores valores no componente da atração, definiu-se denominá-lo como localidades de baixa migração com tendência a atração (BM-atração). No caso do cluster 5, por apresentar maiores valores na repulsão, foi denominado de localidades de baixa migração com tendência a repulsão (BM-repulsão). Estas leves tendências de atração e repulsão podem revelar ainda que tais localidades guardam a inércia de processos que, no passado, tiveram importância na rede migratória nacional, mas que vêm sendo suprimidos com a emergência dos novos padrões.

Finalmente, a análise da distribuição dos valores médios para o cluster 4 mostra a emergência de um padrão bem diferenciado dos anteriores. As 27 localidades integrantes deste grupo mostraram uma média muito alta no componente da rotatividade $(7,829)$ se comparadas às médias dos outros clusters, que ficaram todas abaixo de 1 . 0 cluster ainda apresentou o segundo maior valor no componente de atração $(1,304)$ e no de repulsão $(0,049)$. Dessa forma, pode-se considerar que este grupo é composto de localidades de grande porte populacional, nos quais a migração decisivamente tem importância para a dinâmica demográfica. Contudo, não é possivel afirmar que tais localidades tendem a atrair ou a repelir os migrantes; na verdade, parece que os dois fenômenos acontecem simultaneamente e com a mesma intensidade. Tal padrão migratório certamente configura um desafio no campo teórico, pois caracteriza ambientes de forte circularidade para os migrantes. Assim, esse cluster foi denominado de localidades de rotatividade. 
Com a finalidade de descrever melhor as características de cada cluster, o Gráfico 1 apresenta a dispersão das seis variáveis originais, utilizadas para estimar os componentes principais, segundo os clusters. Na comparação com o saldo migratório, é possível notar maior variabilidade apenas entre as localidades rotativas, fato esperado, já que a rotatividade caracteriza-se pelo alto número de entradas e saídas.

\section{GRÁFICO 1}

Dispersão das variáveis originais, segundo os clusters Brasil - 1995-2000

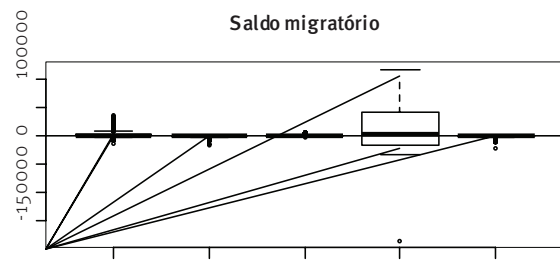

Atração Repulsão BM-Atração Rotativo BM-Repulsão

Percentual de imigrantes na localidade

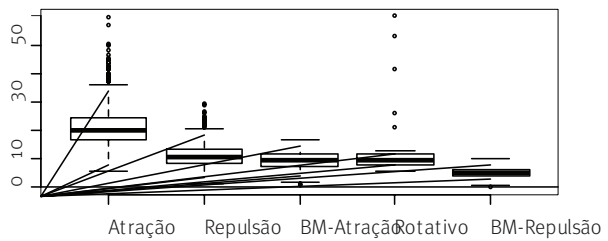

Grau de centralidade

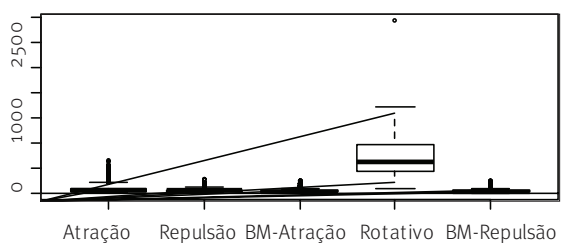

Tamanho populacional

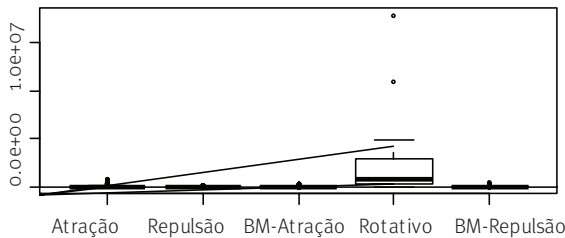

Percentual de emigrantes na localidade

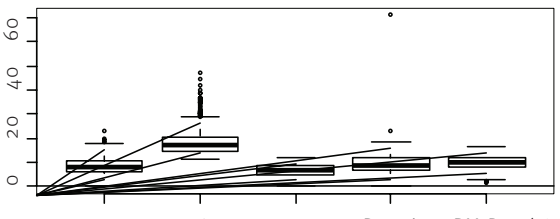

Atração Repulsão BM-Atração Rotativo BM-Repulsão

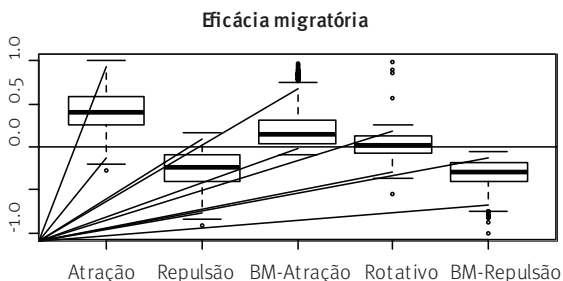

Fonte: IBGE. Censo Demográfico de 2000.

O conjunto de lugares com tendências de atração e repulsão seguiram o padrão esperado, com exceção de algumas localidades consideradas atrativas, que apresentaram saldo migratório negativo no período. Como o método converge os padrões com base na interação entre as seis variáveis, pode-se considerar que esses lugares reúnem as características necessárias para se tornarem centros de atração populacional, mas não são capazes de fazê-lo por alguma razão. A análise mais acurada destes espaços certamente configura uma instigante questão de pesquisa.

Nas outras comparações merece destaque o fato de que as localidades com tendências rotativas apresentam maior variabilidade em torno da população total e do grau de 
centralidade. De fato, esses espaços mostram ser diferenciados do restante das localidades quanto ao porte demográfico e à capacidade de estabelecer conexões. Tendo em conta a eficácia migratória, essas localidades confirmam o padrão de circularidade, concentrando-se em torno do valor zero. Em todos os casos, as localidades de baixa migração dispuseram de uma dispersão menor ou igual que aquelas classificadas como de atração ou repulsão. Tal fato confirma que esses grupos de lugares estão identificando conjuntos distintos de padrões migratórios, em função das diferenças de intensidade com que as variáveis se distribuem em cada cluster.

Além desta verificação descritiva, é possível confirmar a coerência da análise de cluster a partir da espacialização dos grupos. A Figura 1 apresenta dois mapas temáticos, confrontando uma visão do território nacional na qual os municípios se subdividem entre atração e repulsão, ou seja, saldo migratório positivo e negativo, e a divisão aqui proposta de cinco tendências migratórias. Um primeiro importante fator a se considerar na análise dos mapas é que existe um óbvio diálogo entre as representações. Tomando a distribuição das localidades no CentroOeste e sul da Região Norte, os mapas são praticamente idênticos. Ademais, ao se tomar a baixa migração com suas tendências e transpor isso para o primeiro mapa, é possível notar que a análise de cluster apenas qualificou dois níveis distintos de atração e repulsão, tendo em conta a importância da migração para as localidades.

Essa mera separação entre níveis de atração ou repulsão, contudo, ganha forte significado ao ser georreferenciada. O mapa mostra claramente que a porção oeste do Brasil define os contornos dos novos padrões de atração e repulsão populacional, padrões estes que se diferenciam dos fenômenos observáveis nas Regiões Sudeste e Nordeste, por exemplo.

Quanto à rotatividade migratória, já é possível perceber que ela não se concentra em nenhum espaço, sendo observada nas nove regiões metropolitanas e em outros municípios de maior porte que parecem exercer papel central na redistribuição populacional nos contextos regional e nacional. A Figura 2 apresenta os mesmos cinco clusters representados em cinco mapas de pontos, georreferenciados na coordenada geográfica da sede dos municípios e dos centros das regiões metropolitanas. Essa forma de representação permite uma visualização melhor de cada padrão pelo território.

Ao se contrastarem as localidades de atração com as de BM-atração e as de repulsão com as de BM-repulsão, nota-se claramente uma separação espacial do fenômeno. Como já explicitado anteriormente, as Regiões Centro-Oeste e Norte concentram as localidades caracterizadas pela ação das forças atrativas e repulsivas. Ao longo das conexões dadas pelos eixos rodoviários, especialmente o eixo Brasília-Belém, há tanto localidades de atração como de repulsão, o que indica forte redistribuição das populações no contexto regional. No caso da baixa migração, nota-se maior concentração de localidades no Nordeste, Sudeste e Sul. Mesmo que haja espaços onde, a exemplo das outras duas categorias, se justaponham a atração e a repulsão, podem-se notar espaços de ação de uma única tendência.

A BM-repulsão se estende por toda a Região Nordeste, conectando-se ao Sudeste especialmente por toda porção leste do Estado de Minas Gerais e Espírito Santo, além do 
norte do Rio Grande do Sul. A BM-atração concentra-se na faixa litorânea da Região Nordeste e, em contraposição à sua categoria oposta, se estende por todo o Estado de São Paulo, Rio de Janeiro e sul de Minas Gerais, além da faixa litorânea da Região Sul.

Quanto à rotatividade, considerando-se que esta categoria concentra as nove regiões metropolitanas e outros municípios de grande porte, ${ }^{7}$ destaca-se o papel da centralidade destes espaços. É possível que os lugares caracterizados pela rotatividade dos migrantes sejam importantes centros da redistribuição populacional nas suas regiões e que já foram centros de atração no passado. Contudo, as novas características das áreas urbanas, com mercados de trabalho altamente seletivos, provavelmente vêm criando e eliminando oportunidades de forma simultânea. Estudar as características dos imigrantes e emigrantes destas localidades certamente pode lançar mais luz sobre os contornos deste processo.

FIGURA 1

Saldo migratório e tendência migratória dos municípios e regiões metropolitanas brasileiras 1995-2000

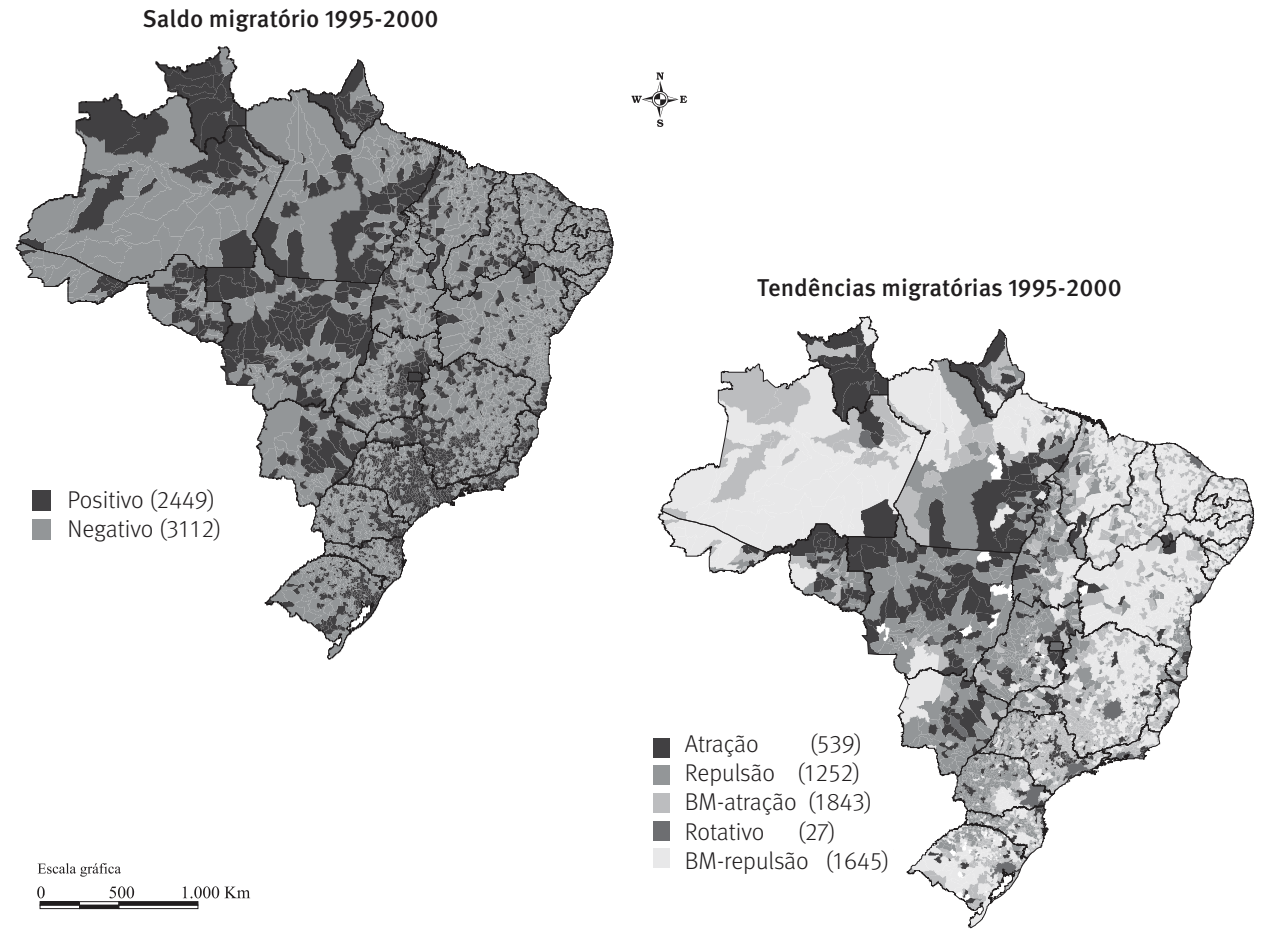

Fonte: IBGE. Censo Demográfico de 2000. Malha digital IBGE.

\footnotetext{
${ }_{7}$ Além das nove regiões metropolitanas supracitadas, foram considerados rotativos os seguintes municípios: Buritis (RO), Manaus (AM), São Luiz (RR), Palmas (TO), Imperatriz (MA), São Luís (MA), Natal (RN), Aracaju (SE), Vitória (ES), Campinas (SP), Ribeirão Preto (SP), Santos (SP), Campo Grande (MS), Cuiabá (MS), Águas Lindas de Goiás (GO), Aparecida de Goiânia (GO), Goiânia (GO) e Brasília (DF).
} 
FIGURA 2

Tendência migratória dos municípios e regiões metropolitanas brasileiras 1995-2000

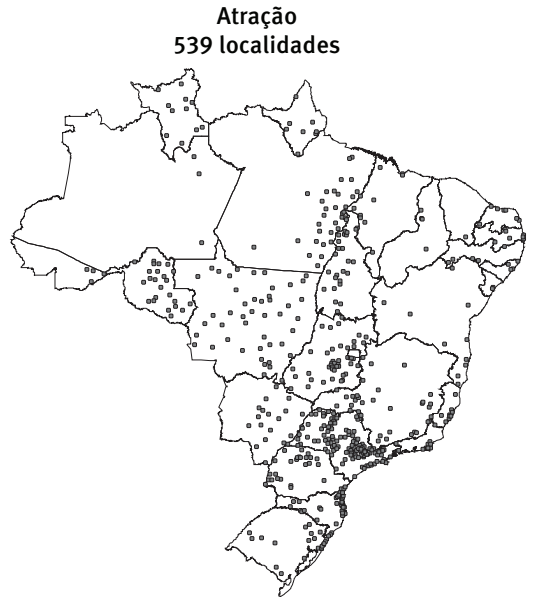

Repulsão

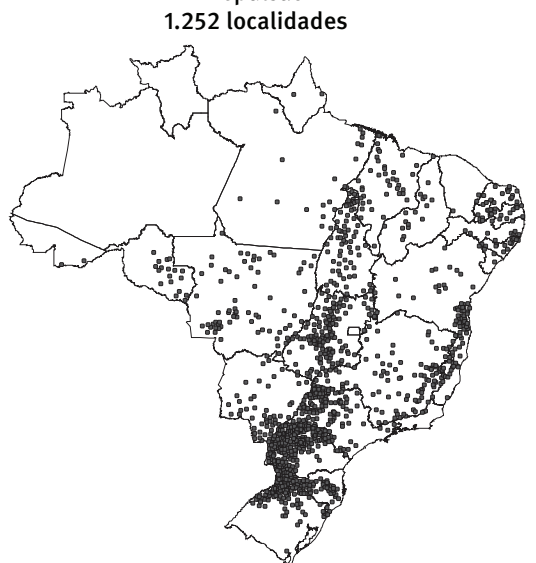

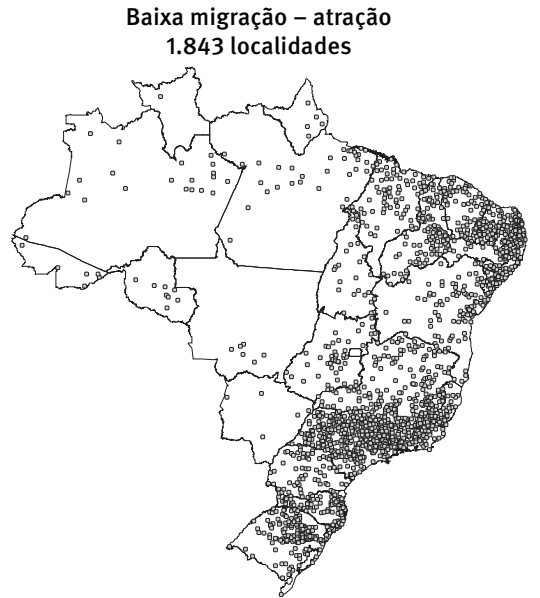

Baixa migração - repulsão 1.645 localidades

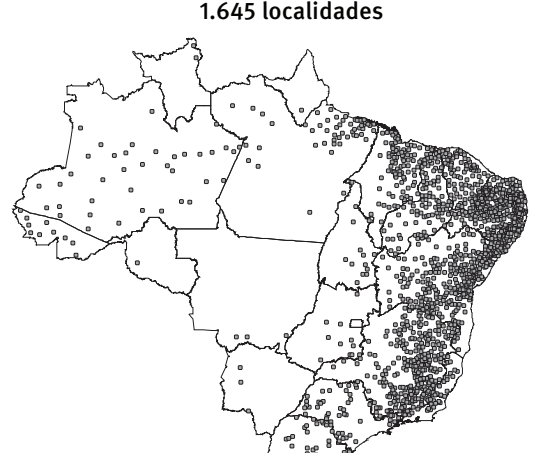

Escala gráfica
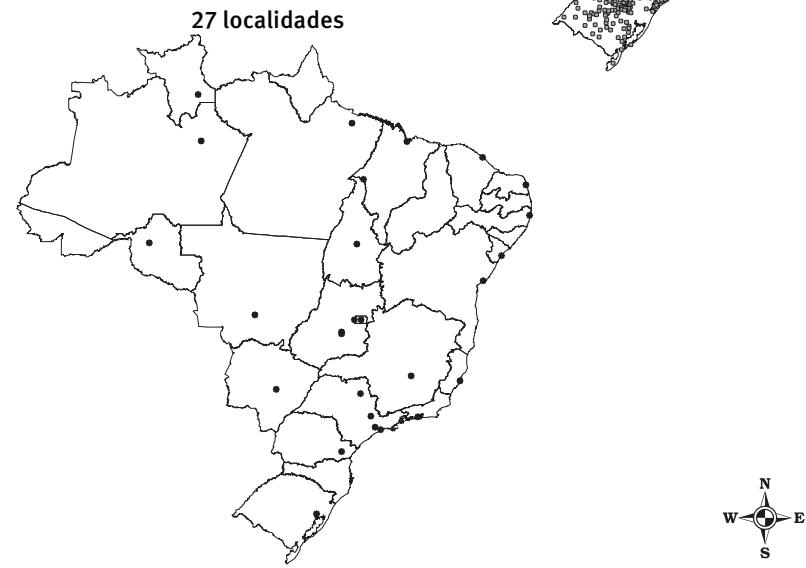

Fonte: IBGE. Censo Demográfico de 2000. Malha digital IBGE. 


\section{Considerações finais}

O estudo das migrações internas brasileiras tem lançado uma série de desafios aos especialistas do tema em função das profundas transformações no cenário econômico, social e demográfico do país nas últimas décadas do século XX. A mobilidade populacional, sem dúvida, é um dos fenômenos mais sensíveis a estas mudanças, tendo em conta que os fluxos migratórios seguem, em boa medida, as direções determinadas pela abertura de novas oportunidades de incrementar as condições de sobrevivência.

A proposta metodológica aqui presente buscou contribuir para a discussão sobre a existência de novos padrões na migração interna brasileira, utilizando recursos da estatística multivariada. Focalizando os estudos nas formas de participação dos lugares na rede migratória nacional, a análise de cluster permitiu visualizar categorias de lugares que sugerem compreensões que vão além da simples divisão dos espaços entre atrativos e repulsivos.

O estudo da rede migratória nacional mostrou que há diferentes níveis de articulação dos lugares no sistema de localidades articulado pelos fluxos migratórios. Isso se expressa na existência de espaços caracteristicamente atrativos e repulsivos, relacionando-se com outros municípios nos quais a migração tem pequena participação na estrutura demográfica das populações. A identificação de lugares mais ou menos articulados com a rede migratória apenas confirma o fato de que os novos padrões da migração caracterizam-se pela sobreposição de novas condições (aumento da circularidade, pulverização da migração no território, etc.) e novos lugares (as grandes cidades, no caso da rotatividade, e as áreas urbanas de porte médio no Centro-sul e Norte, no caso da atração migratória) disponíveis para os movimentos, bem como de padrões antigos que ainda se sustentam como efeito da inércia provocada pela estabilidade dos laços sociais entre os migrantes.

Além disso, destacam-se os grandes aglomerados urbanos, cuja característica principal é a rotatividade migratória e cuja participação no conjunto das trocas populacionais merece investigações mais acuradas, já que lançam perguntas ainda sem resposta: será a rotatividade migratória a característica das migrações no Brasil pós-moderno? Os grandes aglomerados populacionais tenderão a ser todos rotativos? Como se diferenciam os migrantes envolvidos com os lugares rotativos diante daqueles que migram para as outras categorias de lugares? Na ausência destas respostas, resta apenas continuar indagando o fenômeno através dos desafios teóricos e empíricos revelados por estudos desta natureza.

\section{Referências}

BAENINGER, R. Rotatividade migratória: um novo olhar para as migrações no século XXI. In: XVI ENCONTRO NACIONAL DE ESTUDOS POPULACIONAIS. Anais... Caxambu: Associação Brasileira de Estudos Populacionais - Abep, setembro/outubro de 2008. Disponível em: 〈http://www.abep.nepo. unicamp.br/encontro2008/docsPDF/ABEP2008_1254.pdf>.

BORJAS, G. J. Labor economics. Massachusetts: McGraw-Hill, 1996.

BRITO, F. O deslocamento da população brasileira para as metrópoles. Estudos Avançados, v. 20, n. 57, p.221-236, 2006. 
CASTELLS, M. A sociedade em rede. Rio de Janeiro: Paz e Terra, 1999.

. A era da informação. A sociedade em rede. Rio de Janeiro: Paz e Terra, 1999.

DARLINGTON, R. B. Factor analysis, 2010. Disponível em: 〈http://www.psych.cornell.edu/Darlington / factor.htm>. Acesso em: 20 mar. 2010.

FRALEY, C.; RAFTERY, A. E. How many clusters? Which clustering method? Answers via model-based cluster analysis. Computer Journal, n.4, p. 578-588, 1998.

GAUDEMAR, J. P. Mobilidade do trabalho e acumulação do capital. Lisboa: Editorial Estampa, 1977.

GOLGHER, A. B. Diagnóstico do processo migratório no Brasil 4: migração entre municípios. Belo Horizonte: UFMG/Cedeplar, 2006 (Textos para discussão, 285).

HAESBAERT, R. 0 mito da desterritorialização: do fim dos territórios a multiterritorialidade. Rio de Janeiro: Bertrand Brasil, 2004.

HARRIS, J. H.; TODARO, M. P Migração, desemprego e desenvolvimento: uma análise com dois setores. In: MOURA, H. A. (Org.). Migração interna, textos selecionados: teorias e métodos de análise. Fortaleza: BNB, tomo 1, 1980, p. 173-209.

IBGE - Instituto Brasileiro de Geografia e Estatística. Censo Demográfico 2000: documentação dos microdados da amostra. Rio de Janeiro, 2002.

LEE, E. Uma teoria sobre a migração. In: MOURA, H. A. (Org.). Migração interna, textos selecionados: teorias e métodos de análise. Fortaleza: BNB, 1980, p. 89-114.

MATOS, R. E. S. A contribuição dos imigrantes em áreas de desconcentração demográfica do Brasil contemporâneo. Revista Brasileira de Estudos de População, v. 19, n. 1, p. 49-72, 2002.

. Questões teóricas acerca dos processos de concentração e desconcentração da população. Revista Brasileira de Estudos de População, v. 12, n. 1-2, p. 35-58, 1995.

MINGOTI, S. A. Análise de dados através de métodos de estatística multivariada - uma abordagem aplicada. Belo Horizonte: UFMG Press, 2007.

PACHECO, C. A.; Patarra, N. Movimentos migratórios nos anos 80: novos padrões? In: ENCONTRO NACIONALSOBRE MIGRAÇÕES. Anais... Curitiba: Associação Brasileira de Estudos Populacionais - Abep, 1997. Disponível em: 〈http://www.abep.nepo.unicamp.br/docs/anais/outros/1EncNacSobreMigracao/ AnaisENSMigracaoCuritiba1997p445a462.pdf〉.

RAFFESTIN, C. Por uma Geografia do poder. São Paulo: Ática, 1993.

RODRIGUES, P. C.; BRANCO, J. A. A análise de componentes principais sobre dados dependentes. 2006. Disponivel em: 〈http://www.spe2006.ubi.pt/Files/apres/A\%20an\%C3\%A1lise\%20de\%20 componentes\%20principais\%20sobre\%20dados\%20dependentes.pdf〉.

SANTOS, M. A natureza do espaço. 2 ed. São Paulo: Editora Hucitec, 1997.

SINGER, P. Migrações internas: considerações teóricas sobre o seu estudo. In: MOURA, H. A. (Org.). Migração interna, textos selecionados: teorias e métodos de análise. Fortaleza: BNB, tomo 1, 1980, p. 211-244.

SJAASTAD, L. A. Os custos e os retornos da migração. In: MOURA, H. A. (Org.). Migração interna, textos selecionados: teorias e métodos de análise. Fortaleza: BNB, tomo 1, 1980 p. 115-143.

SPSS. The SPSS twostep cluster component - A scalable component enabling more efficient customer segmentation. Technical report, 2001, p. 2-9.

ZHANG, T., RAMAKRISHNON, R.; LIVNY, M. B. An efficient data clustering method for very large databases. Proceedings of the ACM SIGMOD Conference on Management of Data. Montreal, Canada, 1996, p. 103-114. 


\begin{abstract}
From rotative to low migration patterns: an analysis of 1995-2000 patterns of population mobility in Brazil

The authors propose a method for classifying the 5507 municipalities in Brazil according to their characteristics of migration phenomena, as shown in the data now available from the 2000 National Brazilian Census. Multivariate classifications for data reduction and classification analysis were carried out on a set of selected variables that describe how the municipalities in the country are articulated with the overall Brazilian migration network. First a central component analysis was applied in order to reduce the set of original variables into a new set of uncorrelated components. Next these components were used in a classificatory cluster analysis with the purpose of establishing a migration typology for the locations being studied. The results showed that there are great differences among municipalities in their participation in the migration network. There are many municipalities with weak ties with the migration network and a few areas with strong ties, where the populations are very mobile. We have called these municipalities "rotative locations." This classification indicates the existence of new categories of territory beyond the classical definitions of attraction and repulsion, one example being these rotative areas.
\end{abstract}

Keywords: Rotative migration pattern. Low migration. Population mobility.

\title{
Resumen
}

De la rotación migratoria a la baja migración: un análisis de los patrones de la movilidad poblacional en Brasil de 1995-2000

Este trabajo propone una metodología de clasificación de los municipios brasileños según la característica migratoria, utilizando como base las informaciones disponibles en el Censo Demográfico de 2000. Se aplicaron análisis multivariantes de reducción y clasificación de datos sobre un conjunto de variables seleccionadas que describen la forma en la que los 5.507 municipios se articulan en la red migratoria brasileña. En primer lugar se aplicó un análisis de componentes principales con la finalidad de reducir el conjunto de variables originales en componentes no correlacionados entre sí. Posteriormente, estos componentes fueron utilizados en un análisis clasificatorio de cluster, con el objetivo de establecer una tipología migratoria de las localidades en estudio. Los resultados mostraron que hay importantes diferenciales en la inserción de los municipios en la red migratoria, en la que existe un gran número de lugares poco conectados en contraste con un número pequeño de puntos que experimentan fuertes conexiones, y en los cuales la población circula rápidamente. La clasificación señala la existencia de nuevas categorías de lugares, además de las definiciones clásicas de atracción y repulsión, como la rotación migratoria.

Palabras clave: Rotación migratoria. Baja migración. Movilidad poblacional.

Recebido para publicação em 15/06/2011

Aceito para publicação em 20/09/2011 